\title{
Hamstring issues in sports: still a major clinical and research challenge
}

\section{Nikos Malliaropoulos, ${ }^{1,2}$ Nicola Maffulli ${ }^{3}$}

It will not be long until the Olympic 100 metre competitions. As certain as death, taxes and politicians' lies, more than one athlete's 4-year dream will vanish as his or her hamstring tears. This injury remains a great challenge in clinical practice and academic research. This issue of BJSM, with its striking cover, provides insights into the mechanisms that underpin hamstring injuries, guidance for clinical practice and suggestions for future research.

\section{Debate - when do hamstring tears occur?} Hamstring tears occur during high-speed running but which phase of the gait cycle is the culprit? In Head to Head, Elizabeth S Chumanov and colleagues (see page 90) from the Universities of Wisconsin and Melbourne provide the conventional wisdom that hamstrings are frequently injured during eccentric overload at the end of the swing phase. Serial iconoclast John W Orchard (see page 88) argues that the early stance phase of sprinting is more likely the culprit but has evaded attention to date. This interesting debate might make you rethink your rehabilitation approach for hamstring injuries and it may prompt coaches to change their training prescription.

\section{Hamstring tears have personalities!}

A main predictor of prognosis after acute hamstring is the mechanism of the injury. The Karolinska Institute's Carl Askling has been a pioneer in highlighting that there exist at least two distinctly different types of acute hamstring injuries. The first occurs during high-speed running and concentric muscle contraction; the injury occurs to the long head of the biceps femoris and the proximal muscle-tendon junction. The

\footnotetext{
${ }^{1}$ National Track \& Field Centre, Sports Injury Clinic, Sports Medicine Clinic of SEGAS, Thessaloniki, Greece ${ }^{2}$ ECOSEP (European College of Sports and Exercise Physicians), www.ecosep.eu

${ }^{3}$ The London School of Medicine and Dentistry Institute of Health Sciences Education Centre for Sports and Exercise Medicine Mile End Hospital, London, UK

Correspondence to Nikos Malliaropoulos, G.Seferi 34, Harilaoy, 54250, Thessaloniki, Greece; contact@sportsmed.gr
}

second occurs during extensive lengthening of the hamstrings, such as with high kicking, sliding tackles and the sagittal splits. This stretching-type injury usually occurs close to the ischial tuberosity afflicting the tendon of the semimembranosus. Read how the type of tear influences rehabilitation and prognosis (see page 86).

\section{Does MRI help?}

Askling has argued MRI diagnosis is helpful for distinguishing the two types of hamstring tears. One of the pioneers of football medicine, Jan Ekstrand from Linköping in Sweden led a terrific collaboration of 23 European professional team to include the largest study characterising the severity of hamstring strain using $\mathrm{MR}$ to date (see page 112). Remarkably, $70 \%$ of hamstring injuries seen in professional football showed no signs of fibre disruption on MRI. Still, these injuries which occurred without imaging alterations caused the majority of days missed due to injury. Useful for clinicians was the finding that MRI grading was closely associated with lay-off times.

\section{Treatment - we are making progress!}

Despite the prevalence of hamstring injuries, there is still no consensus on their management. A systematic review on the effectiveness of therapeutic interventions for acute hamstring injuries is included and shows that only six studies met the inclusion criteria (see page 103). The six studies investigated different interventions, and will influence our knowledge in terms of evidence-based treatments for such injuries.

Hamstring injury has marked consequences for the performance of athletes and their clubs, hence a re-injury is a real nightmare. Moreover, the re-injury rate is $12-41 \%{ }^{1-4}$ with the re-injury usually more severe than the original one, and the time away from sport generally twice as long. Re-injuries in the Ekstrand et al's study (see page 112) constituted up to $16 \%$ of the injuries recorded, all re-injuries occurring to the biceps femoris.

Another Dutch contribution is via a key systematic review by HM de Visser (see page 124). Astutely, they examined the issue of hamstring injury recurrence. Although only five prospective studies that fulfilled the inclusion criteria for the systematic review, risk factors were a larger volume size of initial trauma, a grade 1 hamstring injury and a previous ipsilateral ACL reconstruction. Protection was afforded by undertaking agility/stabilisation exercises. Given the challenges for clinicians permitting return to sport after a hamstring injury, this paper highlighting players at increased risk of recurrence is invaluable for clinicians.

Prevention is a cornerstone for medicine and injury prevention which is a particular focus of BJSM in partnership with the International Olympic Committee (IOC). Jurdan Mendiguchia from Spain examines the inter-relationship between the different factors involved in hamstring strains (see page 81). The aim is to provide a better understanding of this multifactorial injury and therefore, improve its prevention and prediction methods.

\section{ECOSEP}

Have you considered the benefits of ECOSEP - the European College of Sports and Exercise Physicians? ECOSEP aims to promote the highest standards of sports and exercise medicine physicians care. This organisation is very well aware that countries within the European community have, for very good reasons, a broad spectrum of sport and exercise medicine expertise. ECOSEP understands that each country within the EC very rightly sets its own standards but is aware that within the British Isles, faculties of sports and exercise medicine have been established and the National Health Service has accepted sports and exercise medicine as a recognised specialty and instituted a training programme leading to consultant status.

ECOSEP would in no way wish to impose such standards on any other country but it serves to help all parties within the European community to develop sports and exercise medicine (SEM) expertise. To that end, ECOSEP embraces a broad membership of SEM physicians, associated members particularly trainees in SEM and scientific contributors who teach relevant aspects of SEM from various disciplines. ECOSEP also welcomes medical students who wish to specialise in our growing and important specialty. We are hosting the First Medical students' Meeting - The Medical Students ECOSEP SEM days which will take place at Queen Mary's University, London, on 17th and 18th March 2011 (email contact@ sportsmed.gr). 
ECOSEP proposes to establish a mechanism whereby expertise in teaching and research can be shared particularly with those European communities where at present there is no appropriate background of expertise. The first sports and exercise medicine physicians ECOSEP Travelling Fellowship was a great success and you can apply for the 2012 on the website (http:// www.ecosep.eu). ECOSEP is mindful of national aspirations and simply proposes facilitation in other countries.

ECOSEP is committed to achieve excellence in postgraduate SEM physicians education, training, assessment and accreditation throughout the Europe in order to improve the knowledge of SEM physicians. We run on an annual basis sport medicine assessment and rehabilitation courses, and a very unique sports on field trauma emergencies course. Members receive online access to $B J S M$. Overall, the vision that ECOSEP has set itself is to enhance skills and experience of SEM physicians and the health and healthcare of the athletes, patients and the public.

Put Frankfurt, April 2013 in your calendar! One of the main European sports and exercise medicine physicians events is the ECOSEP Congress. This biannual, international, interdisciplinary event attracts participants from all over Europe. The first ECOSEP Congress was held in Thessaloniki, Greece and the second was in London. The ECSOEP organising committee including Professor Nicola Maffulli, Professor John King, Dr Nat Padhiar welcomed all the participants including sports medicine physicians, orthopaedic surgeons, general practitioners, podiatrists, podiatric surgeons, academics, researchers, physiotherapists and representatives from many contributing medical organisations.

The next ECOSEP Congress will take place in Frankfurt from 25th to 27th April 2013. A great team from the Frankfurt Sports Medicine Institute under Professor Heinz Lohrer's leadership, participating medical organisations, Faculty of Sport and Exercise Medicine (FSEM) (UK), EFOST (European Federation of Orthopaedic National Association for Sport Traumatology), Universities QMUL (Queen Mary's School of Medicine and Dentistry, University of London), Barcelona Medical School, Freiburg, Craiova, SEM Centers such as the Isokinetic Medical Group, Thessaloniki SEM Centre and all the ECOSEP
Committees is confident that this will be a great SEM physicians event.

Enjoy this first ever BJSM 'Hamstring' issue and remember to keep in touch with $B J S M$ via the active blog (http://blogs. bmj.com./bjsm). Be among the thousands who benefit from BJSM podcasts (http:// podcasts.bmj.com/bjsm). BJSM is easy to follow via Twitter (@BJSM_BMJ).

\section{Competing interests None.}

Provenance and peer review Commissioned; internally peer reviewed.

Received 21 December 2011

Accepted 21 December 2011

Br J Sports Med 2012;46:79-80.

doi:10.1136/bjsports-2011-090900

\section{REFERENCES}

1. Malliaropoulos N, Papalexandris S, Papalada A, et al. The role of stretching in rehabilitation of hamstring injuries: 80 athletes follow-up. Med Sci Sports Exerc 2004;36:756-9.

2. Malliaropoulos N, Papacostas E, Kiritsi O, et al. Posterior thigh muscle injuries in elite track and field athletes. Am J Sports Med 2010;38:1813-19.

3. Malliaropoulos N, Isinkaye T, Tsitas K, et al. Reinjury after acute posterior thigh muscle injuries in elite track and field athletes. Am J Sports Med 2011;39:304-10.

4. Askling CM, Malliaropoulos N, Karlsson J. Highspeed running type or stretching-type of hamstring injuries makes a difference to treatment and prognosis. Br J Sports Med 2011;46:86-7. 